\title{
Risk of cardiovascular disease is suppressed by dietary supplementation with protamine and chitooligosaccharide in Sprague-Dawley rats
}

\author{
NAM-HEE KANG ${ }^{1 *}$, WON KYUNG LEE ${ }^{2 *}$, BO-RIM YI ${ }^{1}$, HYE-RIM LEE $^{1}$, MIN-AH PARK ${ }^{1}$, \\ SANG-KI PARK ${ }^{2}$, HYOUNG KOOK PARK $^{2}$ and KYUNG-CHUL CHOI ${ }^{1}$ \\ ${ }^{1}$ Laboratory of Veterinary Biochemistry and Immunology, College of Veterinary Medicine, \\ Chungbuk National University, Cheongju, Chungbuk 361-763; ${ }^{2}$ LG Household and Health Care Ltd., \\ Jang-dong, Yuseong-gu, Daejeon 305-343, Republic of Korea
}

Received May 21,2012; Accepted September 17, 2012

DOI: $10.3892 / \mathrm{mmr} .2012 .1128$

\begin{abstract}
Protamine from salmon spermaries is a novel dietary protein. Chitooligosaccharide (COS) is an oligosaccharide derived from chitin or chitosan, a long-chain polymer, by chemical or enzymatic hydrolysis. These two compounds are known to enhance lipid metabolism by interrupting the digestion and absorption of fat in the body. Cardiovascular disease (CVD) refers to any type of specific disease that affects the heart and circulatory system. Dyslipidemia, a condition involving high levels of low-density lipoprotein (LDL) cholesterol and low levels of high-density lipoprotein (HDL) cholesterol, is generally known to be a primary cause of CVD development. The risk of CVD is usually associated with the atherogenic index (AI) and cardiac risk factor (CRF). The CVD risk is also closely associated with serum levels of total cholesterol (T-CHO), LDL cholesterol and HDL cholesterol. In the present study, we evaluated alterations in serum lipid contents following the administration of protamine, $\mathrm{COS}$ and mixtures of these two compounds to male SpragueDawley (SD) rats, and their ability to reduce CVD risk. Based on the results of a serum lipid assay, protamine, COS and their mixtures were found to significantly reduce AI, CRF and CVD risk by decreasing serum levels of TG, T-CHO and LDL cholesterol and increasing serum HDL cholesterol levels. By contrast, TG and T-CHO concentrations in feces were markedly increased. Accumulation of lipids in the liver tissues of the SD rats fed high-fat diets was also inhibited by the intake
\end{abstract}

Correspondence to: Professor Kyung-Chul Choi, Laboratory of Veterinary Biochemistry and Immunology, College of Veterinary Medicine, Chungbuk National University, 12 Gaesin-dong, Cheongju, Chungbuk 361-763, Republic of Korea

E-mail:kchoi@cbu.ac.kr

*Contributed equally

Key words: protamine, chitooligosaccharide, cardiovascular disease, high-fat diet, triglyceride, cholesterol of protamine and COS. Our findings suggest that protamine, COS and combinations of the two compounds may be used as a dietary therapy for preventing CVD due to their suppressive effects on hyperlipidemia and hypercholesterolemia.

\section{Introduction}

Cardiovascular disease (CVD) refers to any disorder that affects the heart and/or circulatory system. This includes coronary heart disease, cardiomyopathy, ischemic heart disease, atherosclerosis and congestive heart failure. CVD has been the most common cause of mortality worldwide over the last two decades (1) and has increased the economic burden due to the high costs of medical treatment $(2,3)$. The causative factors of CVD include obesity, diabetes, high blood pressure, high blood cholesterol, smoking and family history. Among these factors, hypercholesterolemia and unhealthy ratios of the two smallest lipoprotein cholesterols, low-density lipoprotein (LDL) cholesterol and high-density lipoprotein (HDL) cholesterol, resulting from a high-fat diet and impaired lipid metabolism have been closely linked to CVD incidence and mortality $(4,5)$. LDL cholesterol is often referred to as bad cholesterol since, while circulating through the bloodstream, it tends to form deposits in the walls of the arteries, thereby decreasing artery diameter and resulting in atherosclerosis. Conversely, HDL cholesterol is referred to as good cholesterol since it is able to maintain the healthy state of the inner blood vessel walls by scavenging and recycling cholesterol by transporting it to the liver where it is reprocessed (6,7). Accordingly, the blood levels of LDL and HDL cholesterol are closely associated with the development of CVD and the LDL cholesterol/HDL cholesterol ratio is used to calculate the CVD risk factor $(4,5)$. To reduce the incidence of CVD by achieving the desirable balance between HDL and LDL cholesterol levels, dietary therapy may be considered as a first line treatment.

In the present study, we evaluated dietary supplementation with protamine and chitooligosaccharide (COS) as a potential anti-CVD therapy. Protamine is a protein from salmon sperm which contains high levels of arginine, a basic amino acid, and helps to prevent DNA damage (8). In addition, protamine 
restricts fat absorption in the intestine (9) by markedly inhibiting triglyceride (TG) hydrolysis (10), a process required for the absorption of lipids in the intestine (11). COS is an oligosaccharide made from chitin or chitosan, a long-chain polymer of $\mathrm{N}$-acetylglucosamine, by chemical or enzymatic hydrolysis (12). Chitin and chitosan have limited use as nutrient sources due to their low solubility and high viscosity resulting from their polymeric structures $(12,13)$. By contrast, COS is widely used in food, pharmaceutical and medicinal formulations as a biomaterial due to its high solubility, low molecular weight, low viscosity and non-toxicity (14-16). According to a recent study, COS restores healthy blood pressure, reduces cholesterol levels and prevents alcoholic liver disease (17). In addition, COS exerts protective effects against infections and enhances antitumor activity (18). COS has also been shown to reduce plasma lipid levels in healthy men and TG levels in obese diabetic mice (19-21).

The aim of this study was to evaluate the abilities of protamine, COS and a mixture of the two compounds to reduce CVD risk in vivo. We measured the TG, total cholesterol (T-CHO), LDL cholesterol and HDL cholesterol levels in serum and feces following the dietary administration of protamine, COS and combinations of the two to male Sprague Dawley (SD) rats fed a high-fat diet. We also examined their effects on lipid accumulation in the rat liver tissues by histochemical analysis. Alterations in lipid metabolism resulting from the experimental diets including protamine and COS demonstrated that these two compounds help to regulate hyperlipidemia and hypercholesterolemia, thereby decreasing CVD risk in vivo.

\section{Materials and methods}

Animal adaptation. Healthy male SD rats were purchased from Central Laboratory Animal, Inc. (Seoul, Korea). The 7-week-old male SD rats were housed in a conventional animal facility at the Laboratory Animal Research Center of Chungbuk National University (Cheongju, Korea). The animals were allowed to acclimate for 1 week after arrival. The rats were used for in vivo experiments in accordance with the approved institutional guidelines of Chungbuk National University.

High-fat and experimental diet preparation. Salmon protamine (98\% purity; hydrochloride salt; Maruha Nichiro Foods, Tokyo, Japan) and COS (88\% purity; CNA Biotech, Cheongwon, Korea) were provided by LG Household and Health Care Ltd. (Daejeon, Korea). A high-fat diet was prepared as a corn oil suspension by mixing $6 \mathrm{ml}$ corn oil (Sigma-Aldrich, St. Louis, MO, USA), $80 \mathrm{mg}$ cholic acid (Sigma-Aldrich), 2 mg cholesteryl oleate (Sigma-Aldrich) and $1 \mathrm{mg}$ margarine (Seoul Milk Ltd., Seoul, Korea) in $6 \mathrm{ml}$ distilled water (22). The experimental diets were made by adding protamine, COS and a mixture of the two to the corn oil suspension in high and low doses.

Administration of experimental diets to rats. Male SD rats weighing $323.78 \pm 4.80 \mathrm{~g}$ were divided into seven groups; $3 \mathrm{ml}$ of each experimental diet was orally administered once to each rat in the relevant group via a Zonde needle. The vehicle group ( $n=5)$ was treated with the corn oil suspension alone. The experimental groups (each group, $n=5$ ) were administered the experimental diets of protamine, COS or a mixture of the two with the corn oil suspension. The treatment groups were: i) $\mathrm{P} 100,100 \mathrm{mg}$ protamine/ $\mathrm{kg}$ body weight (bw); ii) $\mathrm{O} 300$, $300 \mathrm{mg} \mathrm{COS} / \mathrm{kg}$ bw; iii) PO100/300, $100 \mathrm{mg}$ protamine $/ \mathrm{kg}$ bw and $300 \mathrm{mg} \mathrm{COS} / \mathrm{kg}$ bw; iv) P8.3, $8.3 \mathrm{mg}$ protamine $/ \mathrm{kg}$ bw; v) O25, $25 \mathrm{mg} \mathrm{COS} / \mathrm{kg}$ bw; and vi) PO8.3/25, $8.3 \mathrm{mg}$ protamine $/ \mathrm{kg}$ bw and $25 \mathrm{mg} \mathrm{COS} / \mathrm{kg}$ bw. Prior to the oral administration of the experimental diets, the rats were starved for $18 \mathrm{~h}$ and blood samples were collected from the tail vein $(0 \mathrm{~h})$. Following the oral administration of the diet, blood samples were collected at 3,9 and $24 \mathrm{~h}$. Feces were collected from each group at the same time points and stored at $-20^{\circ} \mathrm{C}$ until analysis.

Analysis of serum and fecal lipids. Blood (0.5-1 ml) was collected using a Vacuum Serum Separation Tube (SST; Green Cross Corp., Yongin, Gyeonggi, Korea) and left at room temperature for $1 \mathrm{~h}$. Serum was isolated from the blood samples by centrifuging at $3,000 \mathrm{rpm}$ at $4^{\circ} \mathrm{C}$ for $20 \mathrm{~min}$ and then stored at $-20^{\circ} \mathrm{C}$. Serum analysis was conducted using a Hitachi Clinical Analyzer 7080 (Hitachi Korea, Ltd., Seoul, Korea) to measure the serum concentrations of various lipid components, including TG, T-CHO, HDL cholesterol and LDL cholesterol. The atherogenic index (AI), cardiac risk factor (CRF) and CVD risk were determined based on serum LDL cholesterol, HDL cholesterol and T-CHO concentrations. The AI was calculated as (T-CHO - HDL cholesterol)/HDL cholesterol, the CRF was calculated as (T-CHO/HDL cholesterol) and the CVD risk was calculated as (LDL cholesterol/HDL cholesterol).

Rat feces from each group was collected for fecal lipid analysis, and then fecal crude fat was extracted according to the Rose-Gottlieb method (23). For this procedure, $5 \mathrm{~g}$ feces were placed into a Mojonnier fat extractor, $6 \mathrm{ml} \mathrm{NH} \mathrm{NH}_{4} \mathrm{OH}$ (OCI Co., Ltd., Ulsan, Korea) was added and the mixture was left for $3 \mathrm{~min}$. This mixture was combined with $12 \mathrm{ml} \mathrm{95 \%}$ alcohol (OCI Co., Ltd.), $25 \mathrm{ml}$ diethyl ether (OCI Co., Ltd.) and $25 \mathrm{ml}$ petroleum ether (OCI Co., Ltd.) and then left at room temperature for 1-2 h. Finally, fecal crude fat was collected by withdrawing the ether phase at $75^{\circ} \mathrm{C}$ and analyzed to determine the TG and T-CHO levels. Fecal TG was measured with a triglyceride assay kit (Cayman Chemical Co., Ann Arbor, MI, USA) and fecal T-CHO was analyzed with an Enzychrome cholesterol assay kit (BioAssay Systems, Hayward, CA, USA) according to the manufacturer's instructions.

Histological analysis by Oil Red O staining. Twenty-four hours after the oral administration of the experimental diets, liver tissues were harvested from the sacrificed rats and immediately frozen in a deep freezer at $-80^{\circ} \mathrm{C}$. The frozen liver tissues were cryo-sectioned (6- $\mu \mathrm{m}$ thick), fixed in a $10 \%$ formalin solution (OCI Co., Ltd.) at $4^{\circ} \mathrm{C}$ for $5 \mathrm{~min}$ and then rinsed three times with distilled water. A 5\% Oil Red O working solution was prepared by dissolving Oil Red O powder (Sigma-Aldrich) in propylene glycol (OCI Co., Ltd.) and used to stain the sectioned tissues according to the manufacturer's instructions. Counterstaining was conducted with hematoxylin (Sigma-Aldrich) and the sections were then mounted in glycerine (OCI Co., Ltd.). 

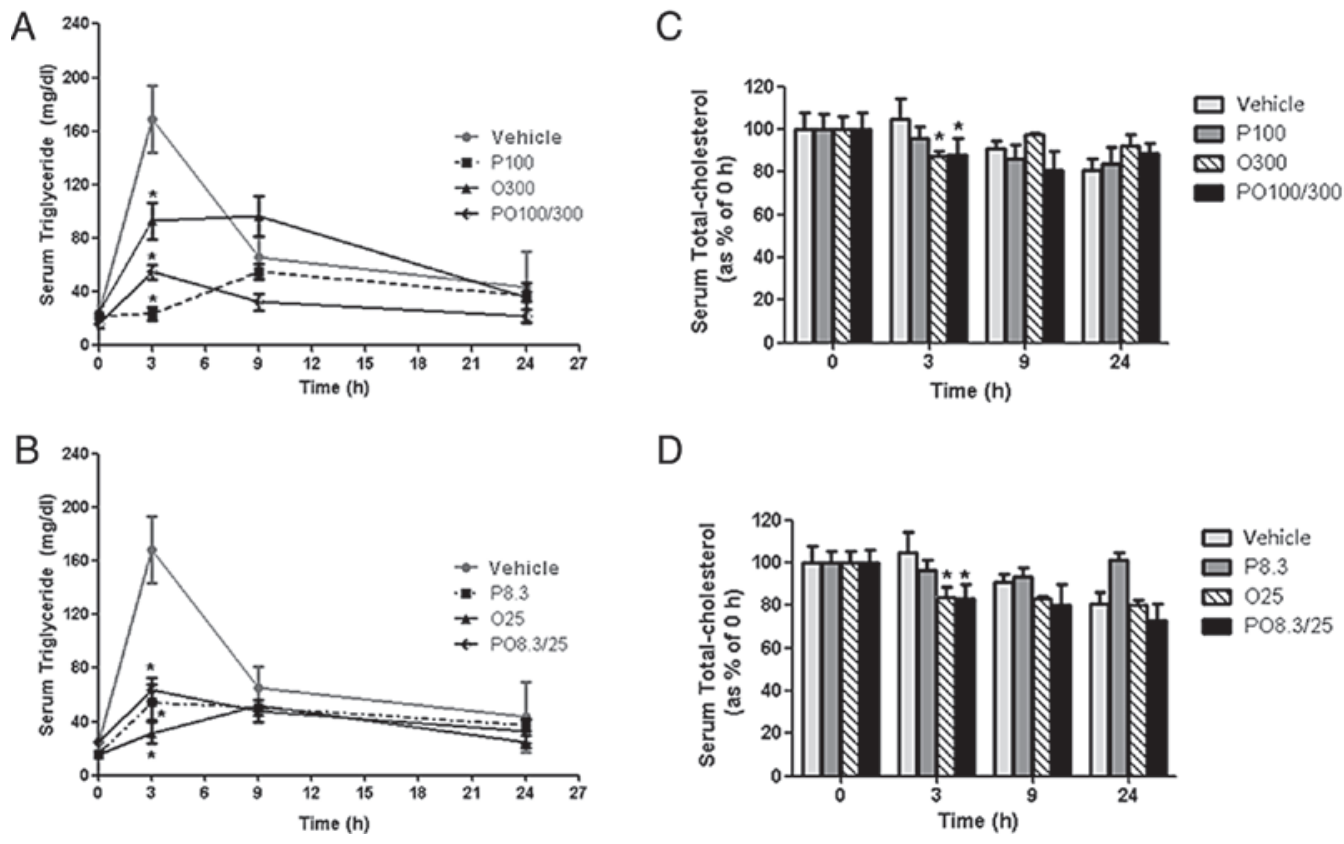

$\mathrm{D}$

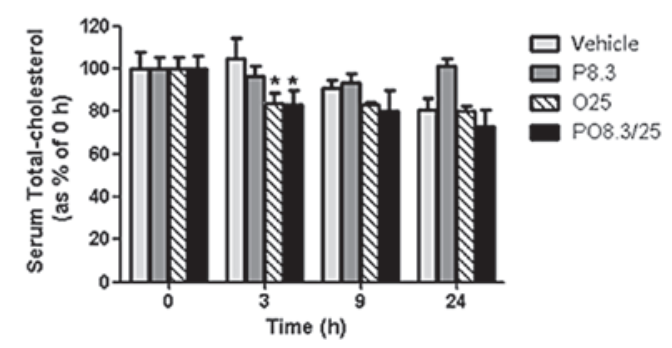

Figure 1. Analysis of triglyceride (TG) and total cholesterol (T-CHO) serum concentrations. Following the oral administration of protamine, chitooligosaccharide (COS) and mixtures of the two compounds in corn oil suspensions, blood samples were collected and left at room temperature. Serum was isolated from the blood samples by centrifuging and the serum concentrations of various lipids were measured. Serum concentrations of (A and B) TG and (C and D) T-CHO in high- and low-dose treatment groups. The treatment groups were: P100, $100 \mathrm{mg}$ protamine $/ \mathrm{kg}$ body weight (bw); O300, 300 mg COS/kg bw; PO100/300, $100 \mathrm{mg}$ protamine $/ \mathrm{kg}$ bw $+300 \mathrm{mg}$ COS $/ \mathrm{kg}$ bw; P8.3, $8.3 \mathrm{mg}$ protamine $/ \mathrm{kg} \mathrm{bw}$; O25, $25 \mathrm{mg}$ COS $/ \mathrm{kg}$ bw; PO8.3/25, $8.3 \mathrm{mg}$ protamine $/ \mathrm{kg}$ bw $+25 \mathrm{mg}$ COS $/ \mathrm{kg}$ bw. Values represent the mean \pm SEM. "Significant elevation compared to vehicle (corn oil) at the same time, $\mathrm{P}<0.05$ (Dunnett's multiple comparison test).

A

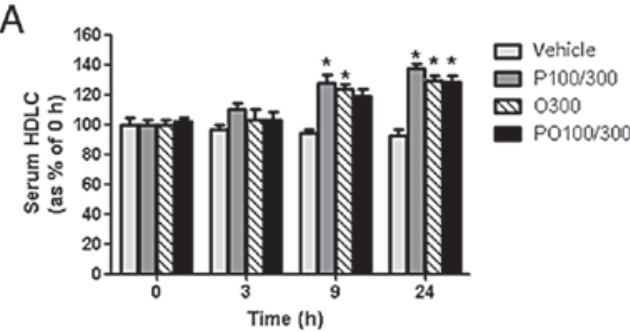

B

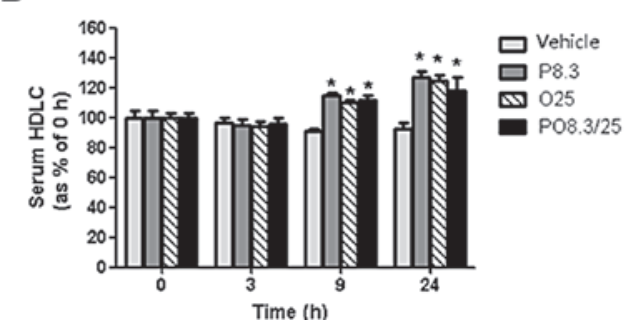

C

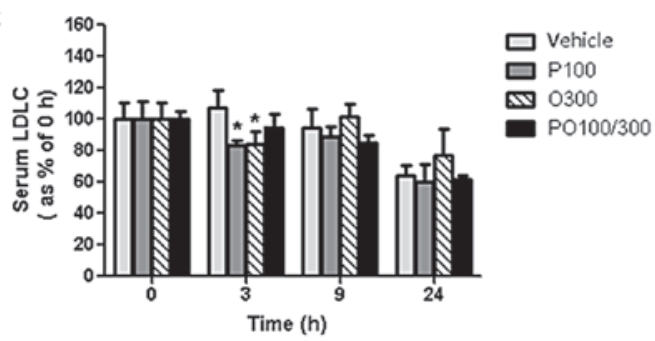

D

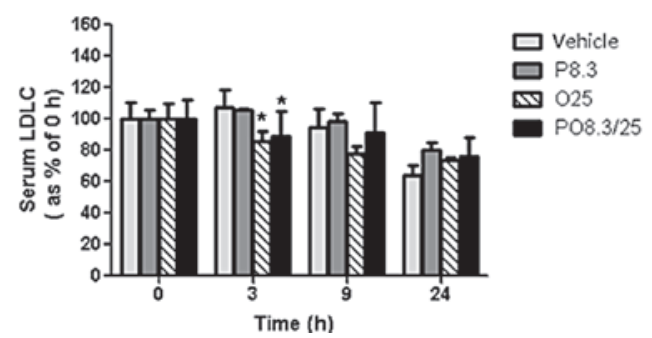

Figure 2. Serum high-density lipoprotein cholesterol (HDLC) and low-density lipoprotein cholesterol (LDLC) analysis. Serum levels of (A and B) HDLC and $(\mathrm{C}$ and D) LDLC for the high- and low-dose treatment groups. The animals were treated as described in Fig. 1. Values represent the mean \pm SEM. "Significant elevation compared to vehicle (corn oil) at the same time, $\mathrm{P}<0.05$ (Dunnett's multiple comparison test).

Lipid-containing cells were detected as those containing red inclusions using a light microscope (BX51 U-LH100HGWIG, Olympus, Tokyo, Japan; magnifications, x40 and x400).

Statistical analysis. Data were analyzed with GraphPad Prism software (San Diego, CA, USA). In vitro data were presented as the mean \pm SEM. One-way ANOVA was performed followed by Dunnett's multiple comparison test. $\mathrm{P}<0.05$ was considered to indicate a statistically significant result (24-26).

\section{Results}

Serum lipid concentrations. Serum TG concentrations in the vehicle control group rapidly increased following the intake of a high-fat diet within $3 \mathrm{~h}$. By contrast, treatment with high and low doses of protamine, COS and their mixtures (P100, O300, PO100/300, P8.3, O25 and PO8.3/25 groups) significantly inhibited serum TG concentrations by $84.3,47.1,51.0,50.7$, 71.0 and $63.0 \%$ at $3 \mathrm{~h}$, respectively, compared with those of the 
Table I. Atherogenic index (AI) of Sprague-Dawley (SD) rats fed a high-fat diet containing protamine, chitooligosaccharide $(\mathrm{COS})$ and a mixture of these two compounds.

\begin{tabular}{lccccccc}
\hline Group & Vehicle $^{\mathrm{a}}$ & P100 & O300 & PO100 & P8.3 & O25 & PO8.3 \\
\hline $\mathrm{AI}^{\mathrm{b}}$ & $1.79 \pm 0.11$ & $1.14 \pm 0.07^{\mathrm{c}}$ & $1.20 \pm 0.19^{\mathrm{c}}$ & $1.25 \pm 0.11^{\mathrm{c}}$ & $1.49 \pm 0.05^{\mathrm{c}}$ & $1.24 \pm 0.08^{\mathrm{c}}$ & $1.29 \pm 0.11^{\mathrm{c}}$ \\
\hline
\end{tabular}

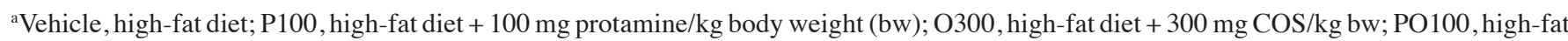
diet + $100 \mathrm{mg}$ protamine $/ \mathrm{kg}$ bw $+300 \mathrm{mg} \mathrm{COS} / \mathrm{kg} \mathrm{bw} ; \mathrm{P} 8.3$, high-fat diet $+8.3 \mathrm{mg}$ protamine $/ \mathrm{kg} \mathrm{bw}$; O25, high-fat diet $+25 \mathrm{mg} \mathrm{COS} / \mathrm{kg}$ bw; PO8.3, high-fat diet $+8.3 \mathrm{mg}$ protamine $/ \mathrm{kg}$ bw $+25 \mathrm{mg} \mathrm{COS} / \mathrm{kg}$ bw. ${ }^{\mathrm{b}} \mathrm{AI}=$ (total cholesterol $-\mathrm{HDL}$ cholesterol)/HDL cholesterol. Results are presented as the mean \pm SEM of three rats per group. ${ }^{\mathrm{C}} \mathrm{P}<0.05$ based on one-way ANOVA (Dunnett's multiple comparison test) results. HDL, high density lipoprotein.

A

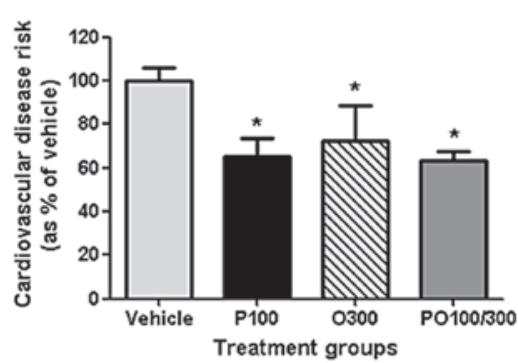

B

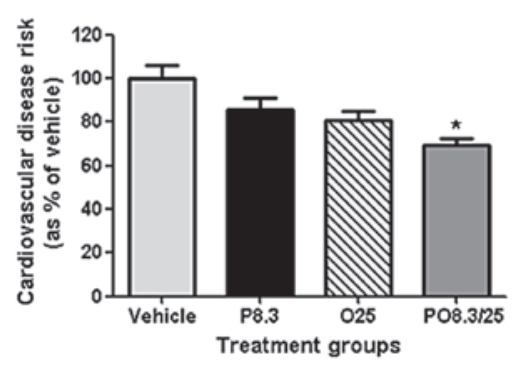

C

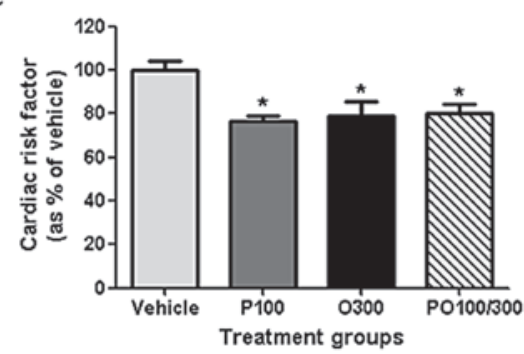

D

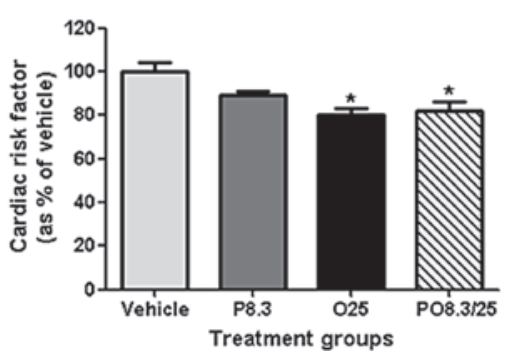

Figure 3. Cardiovascular disease (CVD) risk and cardiac risk factor (CRF) analysis. After measuring serum lipid concentrations, the values of each factor were calculated as described in Materials and methods. (A and B) CVD risks for the high- and low-dose treatment groups. (C and D) CRF for the high- and low-dose treatment groups. Values are the mean \pm SEM. * $\mathrm{P}<0.05$ (Dunnett's multiple comparison test). LDL, low-density lipoprotein; HDL, high-density lipoprotein; $\mathrm{T}-\mathrm{CHO}$, total cholesterol.

vehicle group (Fig. 1A and B). Serum T-CHO concentrations were less effectively reduced compared with the serum TG concentrations. However, the serum T-CHO levels of the $\mathrm{O} 25$ and PO8.3/25 groups were significantly decreased by 19.7 and $20.6 \%$, respectively, at $3 \mathrm{~h}$ compared with those of the vehicle group (Fig. 1C and D). Serum HDL cholesterol concentrations of the P100, O300, PO100/300, P8.3, O25 and PO8.3/25 groups were significantly increased by $32.8,27.3,26.5,25.1$, 23.5 and $19.1 \%$, respectively, at $24 \mathrm{~h}$ compared with those of the vehicle group (Fig. 2A and B). Conversely, the P100, O300, $\mathrm{O} 25$ and PO100/300 treatments decreased serum LDL cholesterol levels by $30.5,37.7,35.6$ and $44.4 \%$, respectively, after $3 \mathrm{~h}$ compared with those of the vehicle control (Fig. 2C and D).

CVD risk factors. The CVD risk, $\mathrm{CRF}$ and $\mathrm{AI}$ of rats fed protamine, $\mathrm{COS}$ or their mixtures were significantly decreased compared with those of the vehicle group (Fig. 3 and Table I). The CVD risk values of the high-dose treatment groups (P100, O300 and PO100/300) were decreased by 34.8, 27.5 and $36.6 \%$, respectively, at $24 \mathrm{~h}$. Among the rats treated with low doses, only the PO8.3/25 group revealed a significantly decreased CVD risk (30.8\%; Fig. 3A and B). The CRF values of the P100, $\mathrm{O} 300$ and $\mathrm{PO} 100 / 300$ groups were decreased by 23.4, 21.2 and $19.5 \%$, respectively, at $24 \mathrm{~h}$. The CRF values of the $\mathrm{O} 25$ and $\mathrm{PO} 8.3 / 25$ groups were decreased by 19.7 and $17.8 \%$, respectively (Fig. 3C and D). The AI values of all treatment groups were significantly decreased (Table I).

Fecal TG and cholesterol concentrations. Protamine, COS, and mixtures of the two significantly increased the TG and $\mathrm{T}$-CHO concentrations in the feces compared with those of the vehicle group in rats fed a high-fat diet. The fecal TG concentrations generally increased over time within $24 \mathrm{~h}$. In particular, the P100 and PO100/300 groups revealed highly increased levels of fecal TG at $9 \mathrm{~h}$. The fecal TG concentrations of the $\mathrm{O} 25$ group also increased significantly at $24 \mathrm{~h}$ $(494.9 \%)$ compared with those of the vehicle group (Fig. 4A and $\mathrm{B}$ ). The fecal T-CHO concentrations of the rats treated with the experimental diets were increased to a lesser degree. The fecal T-CHO concentrations of the P100, O300 and O25 

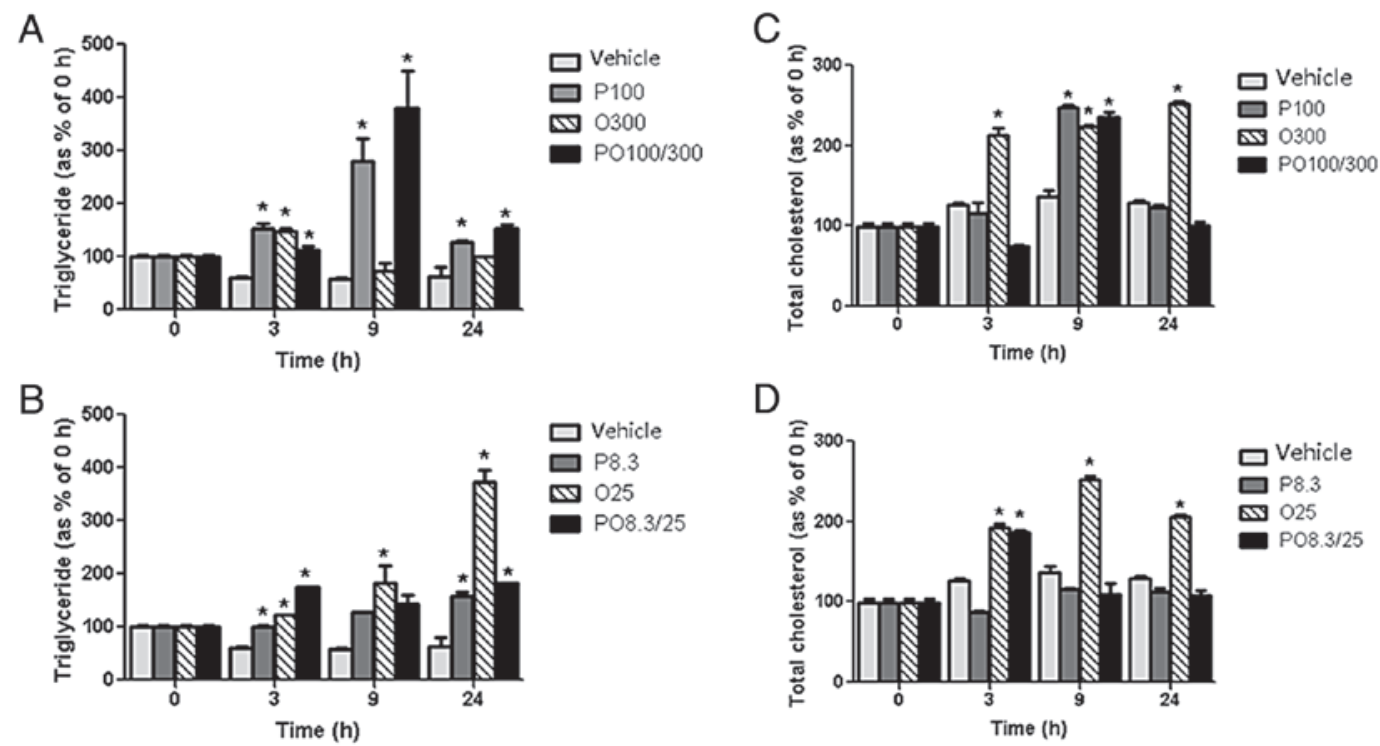

Figure 4. Analysis of fecal lipid concentrations. Following the oral administration of protamine, chitooligosaccharide (COS) and mixtures of the two in corn oil suspension, feces from the rats in each group were collected. Fecal crude fat was then extracted and analyzed for triglyceride (TG) and total cholesterol (T-CHO) content. (A and B) Fecal TG concentrations in the high- and low-dose treatment groups. (C and D) Fecal T-CHO concentrations in the high- and low-dose treatment groups. Values are the mean \pm SEM. *Significant elevation compared to vehicle (corn oil) at the same time, P<0.05 (Dunnett's multiple comparison test).

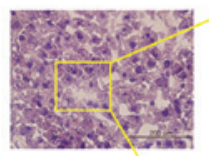

A $\times 400$ Vehicle

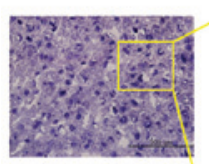

C $\times 400$ $0300 / 025$
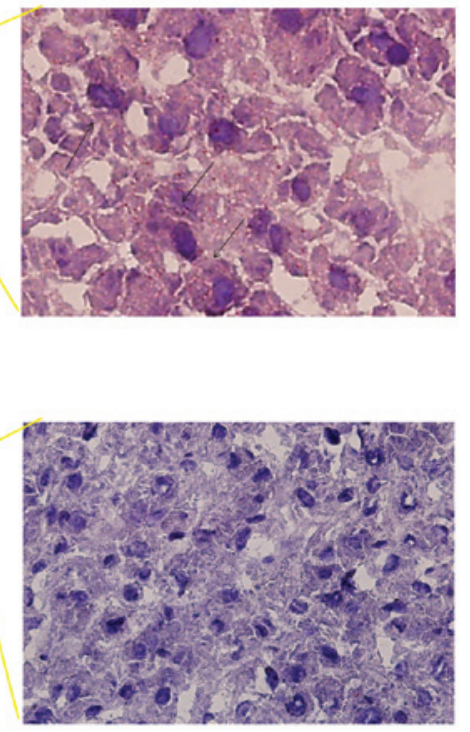

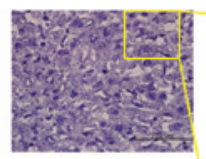

B $\times 400$

P100/8.3
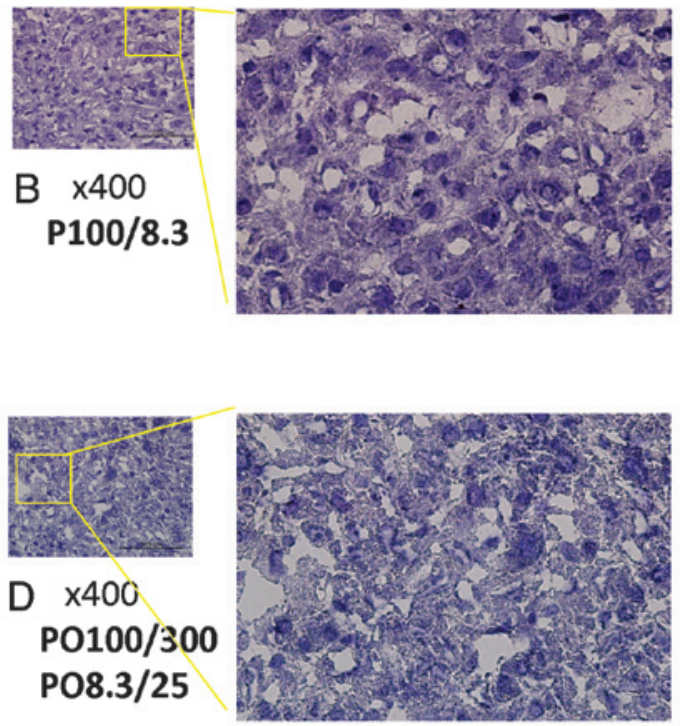

Figure 5. Histological analysis of liver tissues. Following the oral administration of protamine, chitooligosaccharide (COS) and mixtures of these two compounds, liver tissues were harvested from the rats, frozen, cryo-sectioned and stained with an Oil Red O working solution. Counter-staining was conducted with hematoxylin and the tissue sections were then mounted with glycerine. Lipid in the cells appeared as red inclusions under a light microscope (magnification, x400). Liver tissues from (A) vehicle control, (B) protamine-treated, (C) COS-treated and (D) protamine- and COS-treated rats.

groups were increased by $82.2,64.4$ and $84.5 \%$, respectively, at $9 \mathrm{~h}$ (Fig. 4C and D).

Lipid accumulation in liver tissues. Lipid accumulation in the rat liver tissues was detected by Oil Red O staining and histological analysis. The red inclusions corresponded to lipids derived from TG and T-CHO from the high-fat diet. Significant levels of lipid accumulation were observed in the vehicle group, but increases in lipid accumulation were not observed in all experimental diet groups treated with protamine, COS or a mixture of the two compounds (Fig. 5).

\section{Discussion}

A high-fat diet and dysfunctional lipid metabolism are closely associated with the increasing prevalence of being overweight and of obesity, and are influential causes of CVD $(27,28)$. In particular, dyslipidemia, characterized by high levels of very low-density lipoproteins (VLDL) and TG and decreased HDL and LDL levels in the serum, is generally known to be a strong predictor for the development of CVD (29). In the present study, we evaluated the effects of a dietary therapy including protamine and COS, two prominent candidates for 
positively affecting lipid metabolism, on CVD risk in rats. We measured the improvements of lipid metabolism following the administration of protamine, COS and their mixtures in vivo by analyzing serum and fecal lipid levels as well as hepatic lipid accumulation within $24 \mathrm{~h}$ of the oral administration of a high-fat diet along with protamine and COS to SD rats. The dose-dependent effects of protamine $(30,31)$ and COS were also examined. The factors CVD risk, $\mathrm{CRF}$ and $\mathrm{AI}$ were then calculated based on serum T-CHO, HDL cholesterol and LDL cholesterol concentrations.

Protamine, COS and mixtures of the two compounds effectively reduced the serum levels of TG, T-CHO and LDL cholesterol compared with the vehicle. By contrast, these compounds significantly increased the serum levels of HDL cholesterol. When serum cholesterol levels were translated into risk factor values, protamine, $\mathrm{COS}$ and their mixtures were shown to decrease AI, CVD risk and CRF. The AI was significantly reduced in all experimental diet groups compared with the vehicle control group. CVD risk and CRF were also significantly reduced in all rats treated with high doses as well as in the low-dose PO8.3/25 group, indicating that high doses of protamine and COS were more effective than low doses for reducing these risk factors. Additionally, a combination of protamine and COS had greater effects than treatment with protamine or COS alone at low doses. However, the additive effect of protamine and COS was not evident at high doses. We therefore conclude that protamine and COS have effects that are beneficial for the prevention of diseases associated with arteriosclerosis and cardiac failure by improving lipid metabolism.

An unhealthy serum cholesterol profile (higher levels of LDL cholesterol and lower levels of HDL cholesterol) is known to promote atheroma development in atherosclerosis, which is strongly associated with CVD $(32,33)$. Improvement of an unfavorable serum cholesterol profile by dietary supplementation with protamine and COS was achieved by reversing the unhealthy ratio of LDL cholesterol to HDL cholesterol. Serum HDL cholesterol concentrations were significantly increased by protamine and COS. However, the two compounds effectively reduced the serum levels of LDL cholesterol. HDL cholesterol is considered to have a variety of useful actions that tend to reduce the risk for CVD. HDL cholesterol removes and recycles LDL cholesterol by transporting it to the liver, an action which is generally thought to produce a central anti-atherogenic effect (34). A previous study has shown that there is an inverse correlation between HDL levels and the risk of CVD in which the risk of CVD is increased by $14 \%$ with $5 \mathrm{mg} / \mathrm{dl}$ decrements in HDL levels (35).

Unlike in serum, TG and T-CHO concentrations in feces were markedly increased by protamine, COS and their mixtures over the same period of time, indicating that TG and T-CHO were effectively excreted from the body by rats fed the experimental diets. When treated with high doses, the fecal TG concentrations were maximized at $9 \mathrm{~h}$. However, low-dose treatments resulted in the maximum amount of TG being excreted in the feces at $24 \mathrm{~h}$. Fecal T-CHO concentrations were also considerably increased by protamine and COS. Specifically, high-dose COS treatment increased fecal T-CHO levels by the greatest amount. These results demonstrated that protamine, COS and mixtures of the two interrupted lipid accumulation in the liver and blood vessels. This was further shown by histological analysis using Oil Red O staining. Liver tissues obtained from rats fed high-fat diets revealed a large number of lipid inclusions stained with the Oil Red $\mathrm{O}$ working solution, but little lipid accumulation was observed in rats treated with protamine, COS and their mixtures.

In summary, our results demonstrated that protamine, COS and mixtures of the two compounds effectively reduced CVD risk, CRF and AI by decreasing serum levels of TG, T-CHO and LDL cholesterol and enhancing serum HDL cholesterol levels. The reduction of serum TG and T-CHO levels may be explained by the finding that protamine and COS promoted the excretion of TG and T-CHO in feces, thereby preventing accumulation in the body. However, future studies are required to elucidate the mechanism(s) underlying the reduction of CVD risk through beneficial changes in HDL cholesterol/LDL cholesterol ratios due to treatment with protamine, COS and their mixtures. In conclusion, our results suggest that protamine and COS are promising dietary supplements for preventing CVD by alleviating hyperlipidemia and hypercholesterolemia.

\section{Acknowledgements}

This study was supported by a National Research Foundation of Korea (NRF) grant funded by the Ministry of Education, Science and Technology (MEST) of the Republic of Korea government (no. 2011-0015385). In addition, this study was also supported by the Priority Research Centers Program through the NRF funded by the MEST (2011-0031403).

\section{References}

1. Yokokawa H, Yasumura S, Tanno K, et al: Serum low-density lipoprotein to high-density lipoprotein ratio as a predictor of future acute myocardial infarction among men in a 2.7-year cohort study of a Japanese northern rural population. J Atheroscler Thromb 18: 89-98, 2011

2. Bae JM, Yang YJ, Li ZM and Ahn YO: Low cholesterol is associated with mortality from cardiovascular diseases: a dynamic cohort study in Korean adults. J Korean Med Sci 27: 58-63, 2012.

3. Kim JE, Jeon SM, Park KH, et al: Does Glycine max leaves or Garcinia Cambogia promote weight-loss or lower plasma cholesterol in overweight individuals: a randomized control trial. Nutr J 10: $94,2011$.

4. Ingelsson E, Schaefer EJ, Contois JH, et al: Clinical utility of different lipid measures for prediction of coronary heart disease in men and women. JAMA 298: 776-785, 2007.

5. Manninen V, Tenkanen L, Koskinen P, et al: Joint effects of serum triglyceride and LDL cholesterol and HDL cholesterol concentrations on coronary heart disease risk in the Helsinki Heart Study. Implications for treatment. Circulation 85: 37-45, 1992.

6. Lowe ME: Molecular mechanisms of rat and human pancreatic triglyceride lipases. J Nutr 127: 549-557, 1997.

7. Lowe ME: The triglyceride lipases of the pancreas. J Lipid Res 43: 2007-2016, 2002.

8. Aspedon A and Groisman EA: The antibacterial action of protamine: evidence for disruption of cytoplasmic membrane energization in Salmonella typhimurium. Microbiology 142: 3389-3397, 1996.

9. Hosomi R, Fukunaga K, Arai H, Kanda S, Nishiyama T and Yoshida M: Effect of dietary protamine on lipid metabolism in rats. Nutr Res Pract 4: 462-469, 2010.

10. Zhang J, Kang MJ, Kim MJ, et al: Pancreatic lipase inhibitory activity of Taraxacum officinale in vitro and in vivo. Nutr Res Pract 2: 200-203, 2008.

11. Duarte-Vázquez MA, García-Padilla S, Olvera-Ochoa L, et al: Effect of protamine in obesity induced by high-fat diets in rats. Int J Obes (London) 33: 687-692, 2009. 
12. Zhou TX, Chen YJ, Yoo JS, et al: Effects of chitooligosaccharide supplementation on performance, blood characteristics, relative organ weight, and meat quality in broiler chickens. Poult Sci 88: 593-600, 2009.

13. Chae SY, Jang MK and Nah JW: Influence of molecular weight on oral absorption of water soluble chitosans. J Control Release 102: 383-394, 2005

14. Choi BK, Kim KY, Yoo YJ, Oh SJ, Choi JH and Kim CY: In vitro antimicrobial activity of a chitooligosaccharide mixture against Actinobacillus actinomycetemcomitans and Streptococcus mutans. Int J Antimicrob Agents 18: 553-557, 2001.

15. Ju C, Yue W, Yang Z, et al: Antidiabetic effect and mechanism of chitooligosaccharides. Biol Pharm Bull 33: 1511-1516, 2010.

16. Shon YH and Nam KS: Inhibition of polyamine biosynthesis in Acanthamoeba castellanii and 12-O-tetradecanoylphorbol13 -acetate-induced ornithine decarboxylase activity by chitosanoligosaccharide. Biotechnol Lett 25: 701-704, 2003.

17. Cho SY, Lee JH, Song MJ, et al: Effects of chitooligosaccharide lactate salt on sleep deprivation-induced fatigue in mice. Biol Pharm Bull 33: 1128-1132, 2010.

18. Suzuki K, Mikami T, Okawa Y, Tokoro A, Suzuki S and Suzuki M: Antitumor effect of hexa-N-acetylchitohexaose and chitohexaose. Carbohydr Res 151: 403-408, 1986.

19. Choi CR, Kim EK, Kim YS, et al: Chitooligosaccharides decreases plasma lipid levels in healthy men. Int $\mathrm{J}$ Food Sci Nutr 63: 103-106, 2012.

20. Hayashi $\mathrm{K}$ and Ito $\mathrm{M}$ : Antidiabetic action of low molecular weight chitosan in genetically obese diabetic KK-Ay mice. Bio Pharm Bull 25: 188-192, 2002.

21. Tang ZR, Yin YL, Nyachoti CM, et al: Effect of dietary supplementation of chitosan and galacto-mannan-oligosaccharide on serum parameters and the insulin-like growth factor-I mRNA expression in early-weaned piglets. Domest Anim Endocrinol 28: 430-441, 2005

22. Tsujita T, Matsuura Y and Okuda H: Studies on the inhibition of pancreatic and carboxylester lipases by protamine. J Lipid Res 37: 1481-1487, 1996.

23. Gors S, Kucia M, Langhammer M, Junghans $\mathrm{P}$ and Metges CC: Technical note: milk composition in mice - methodological aspects and effects of mouse strain and lactation day. J Dairy Sci 92: 632-637, 2009

24. Kang NH and Choi KC: 207 engineered human amniotic fluid-derived stem cells by expressing cytosine deaminase (cd) and thymidine kinase (hsv-tk) mediate targeting killing effect in breast cancer cells. Reprod Fertil Dev 24: 216, 2012.

25. Kang NH, Yi BR, Lim SY, et al: Human amniotic membranederived epithelial stem cells display anticancer activity in $\mathrm{BALB} / \mathrm{c}$ female nude mice bearing disseminated breast cancer xenografts. Int J Oncol 40: 2022-2028, 2012.
26. Kim KY, Yi BR, Lee HR, et al: Stem cells with fused gene expression of cytosine deaminase and interferon- $\beta$ migrate to human gastric cancer cells and result in synergistic growth inhibition for potential therapeutic use. Int J Oncol 40: 1097-1104, 2012.

27. Haslam DW and James WP: Obesity. Lancet 366: 1197-1209, 2005.

28. Wang $\mathrm{H}$ and Peng DQ: New insights into the mechanism of low high-density lipoprotein cholesterol in obesity. Lipids Health Dis 10: 176, 2012.

29. Poirier P, Giles TD, Bray GA, et al: Obesity and cardiovascular disease: pathophysiology, evaluation, and effect of weight loss: an update of the 1997 American Heart Association Scientific Statement on Obesity and Heart Disease from the Obesity Committee of the Council on Nutrition, Physical Activity, and Metabolism. Circulation 113: 898-918, 2006.

30. Hosomi R, Fukunaga K, Arai H, Nishiyama T and Yoshida M: Effects of dietary fish protein on serum and liver lipid concentrations in rats and the expression of hepatic genes involved in lipid metabolism. J Agric Food Chem 57: 9256-9262, 2009.

31. Moriyama T, Kishimoto K, Nagai K, et al: Soybean betaconglycinin diet suppresses serum triglyceride levels in normal and genetically obese mice by induction of beta-oxidation, downregulation of fatty acid synthase, and inhibition of triglyceride absorption. Biosci Biotechnol Biochem 68: 352-359, 2004.

32. Artenie R, Ungureanu D, Artenie A, Botnariu G and Anisie E: HDL-cholesterol - active or passive participant in the pathogenesis of atherosclerosis. Rev Med Chir Soc Med Nat Iasi 107: 282-287, 2003 (In Romanian).

33. Sancho-Rodriguez N, Avilés-Plaza FV, Granero-Fernandez E, et al: Observational study of lipid profile and LDL particle size in patients with metabolic syndrome. Lipids Health Dis 10: 162, 2011.

34. Shah PK, Kaul S, Nilsson J and Cercek B: Exploiting the vascular protective effects of high-density lipoprotein and its apolipoproteins: an idea whose time for testing is coming, part I. Circulation 104: 2376-2383, 2001

35. Gotto AM Jr, Whitney E, Stein EA, et al: Relation between baseline and on-treatment lipid parameters and first acute major coronary events in the Air Force/Texas Coronary Atherosclerosis Prevention Study (AFCAPS/TexCAPS). Circulation 101: 477-484, 2000 